\title{
Reinventando territórios pela via da diferença: desafios para a Psicologia
}

Temos imensa satisfação em apresentar o número dois de 2018. Usamos esse espaço para, uma vez mais, ilustrar o editorial de forma politicamente consoante com nossa missão, colocando em pauta discussões caras a nós, que procuram inscrever novos territórios para a produção de conhecimento em Psicologia. Em um momento histórico no qual o Estado brasileiro revalida fortemente estratégias de controle na manutenção do instituído e engendrando mais violências, acreditamos que a Psicologia pode ocupar uma posição estratégica de resistência, em defesa de formas de vida balizadas por uma ética da liberdade de expressão e pensamento, da construção de territórios pela via da diferença e da equidade. A presente edição, de forma afim a essa discussão, reúne textos que têm em comum uma valorização da Psicologia em sua dimensão política, ética e estética, diante de seus múltiplos objetos e saberes. Contribuir para o desenvolvimento de um campo de conhecimento e de exercício profissional como proposta chave da Revista Polis e Psique, supõe assumir a responsabilidade de trabalhar pela via da valorização do diálogo.

$\mathrm{Na}$ esteira dessa discussão, cremos que a noção de território pode ser uma estratégica forma de apresentar essa proposta. Em uma perspectiva política, ética e estética de fazer os territórios não se reduzem a uma noção funcionalista, dualista a uma perspectiva cindida de indivíduo e contexto - mas se fazem próximos ao que propõem Deleuze e Guattari (1997), enquanto inscrição de sentidos e expressões. Acreditamos que, frente à monologia violenta das narrativas lineares, dos reducionismos e das formas reativas de vida (Anzaldúa, 1997) que figuram nos retrocessos governamentais, é preciso apostar nas possibilidades de resistência nascentes de uma Psicologia polifônica, aberta ao diálogo, disposta à construção de territórios existenciais num porvir. Essa intrincada disposição da Psicologia para a crise, no seu sentido mais potente, diz da consolidação multifacetada desta área como de produção de conhecimento (Tourinho, 2001; Nardi, 201), mas também da sua potência enquanto criadora de espaços de vida.

Há, portanto, uma proposição nessa proposta política: a luta declarada contra as formas normativas e violentas - fascistas - de confinamento do viver. Portanto, boa parte Rev. Polis e Psique, 2018; 8(2): 1 - 6 
da ênfase editorial da revista está em promover a reflexão - por meio de seus artigos sobre elementos teóricos que fundamentam espaços constituintes dos territórios existenciais, que possibilitam que vejamos o engajamento em pesquisa e produção de conhecimento em um "compartilhamento de um território existencial no qual sujeito e objeto da pesquisa se relacionam e se codeterminam" (Alvarez \& Passos, 2014, p.131). Na Polis e Psique, acreditamos que essa possibilidade se dá na indissociabilidade entre produção de conhecimento e ação política, de modo que possamos constituir o seu fazer como desestabilizador de redes de poder-saber instituídas, que insistem em sufocar as possibilidades de criação de afetos e sensibilidades. Apostando nessa pluralidade como forma propositiva apresentamos, no atual número, uma série de estudos que procuram estudar esses campos de produção pela via de territórios outros, numa posição de potente estranhamento acerca daquilo tomado como naturalizado.

Iniciamos este número apresentando o texto derivado de entrevista com Félix Guattari - Félix Guattari: entrevista para tv grega -, de Anderson dos Santos. O pensador nos apresenta discussões acerca de temas como Filosofia, Amizade, Movimentos Marginais, Ecosofia, Mídias, Subjetividade, Os Anos de Inverno, Europa, Grécia e Depressão. Essa composição proporcionada pela entrevista de Guattari abre espaço para que pensemos certos estrangeirismos e possamos mergulhar em outros territórios. No primeiro artigo deste número - A questão do estrangeiro na contemporaneidade: uma leitura a partir de Zygmunt Bauman -, Rafael Bianchi Silva e Dandara Peraro de Sousa apresentam uma pesquisa em que discutem o atual momento global, marcado por pessoas forçadas a sair de seus países, pela precarização das condições de vida e proteção, na busca por refúgio. $\mathrm{O}$ autor e a autora apontam que, a partir destes movimentos internacionais, levanta-se a necessidade de construir modos de convivência. Para tanto, analisam a problemática do contexto atual de migrações internacionais e a questão do estrangeiro a partir da obra sociólogo polonês Zygmunt Bauman. Elencam, para tanto, a questão do estrangeiro como forasteiro, amparada ao conceito de identidade, considerando a alteridade que se faz presente na relação com o outro e permitindo o reconhecimento desse outro em sua singularidade. Além disto, aponta-se a necessidade de uma nova política vinculada a construção de espaços físicos e simbólicos que viabilizem a vivência da diferença. 
O segundo artigo - Territórios e sistemas vitais na saúde -, de Anita Guazzelli Bernardes e João Arriscado Nunes, procura trazer para análise o conceito de território na saúde. Atenta-se, em especial para as circunstancialidades e os efeitos que se constituem quando o conceito de território torna-se um vetor de produção de práticas em saúde. Nesta perspectiva de trabalho - indicando como o território torna-se, na Política de Saúde, um conceito operacional das práticas, de modo a constituir-se como um vetor de organização e conexão de distintos elementos - o texto mostra como se estabiliza para além de uma demarcação fronteiriça da Nação e assume uma conformação de agenciamento maquínico de corpos, espaços, relações, subjetividades, vida.

No texto Coletividade e histeria: psicanálise e movimentos sociais, Patrícia do Prado Ferreira elabora contribuições que partem das considerações de Freud e Lacan em vistas à dizer da existência de ao menos dois desdobramentos diferentes que se originam do mesmo tipo clínico. Neste sentido, contribuir para uma melhor compreensão das possibilidades e limitações dos movimentos coletivos e grupamentos sociais, especialmente alguns que permearam a cena política brasileira nos últimos tempos. Também pensando a coletividade e os movimentos sociais, o texto de Marcos Ribeiro Mesquita, Ana Cecília Silva , Lívia Barbosa Lima, Juliano Bonfim e Carolina Silva Juventudes, gênero e sexualidade: a ação política dos movimentos sociais - procura descrever os resultados de uma investigação que objetivou analisar e tecer compreensões acerca da visão das e dos jovens sobre as dinâmicas participativas dos grupos e movimentos sociais feministas e LGBTs na atualidade. Discutindo questões referentes à participação política e a relação com as dimensões de gênero e diversidade sexual, essas e esses jovens participantes da pesquisa indicaram uma noção das dinâmicas internas dos coletivos e dos desafios envolvidos. Da experiência pessoal de afirmação e de enfrentamento, o escrito atenta para a desconstrução de discursos naturalizados e essencializados sobre a sexualidade e o gênero. 
Em Análise do vocacional: recriando uma psicologia com favelas, escolhas, jovens, de Thiago Colmenero Cunha, Camila Moreira Crespo, Patrick Silva Botelho e Laiza da Silva Sardinha temos reflexões sobre o cerceamento de escolhas tanto em instituições educacionais quanto em territórios populares que possuem conflitos armados, pondo em pauta o papel da psicologia em orientar, indicar, direcionar vocações sem se questionar ética e politicamente sobre as implicações dessas intervenções. Por meio da aposta na Análise do Vocacional, segundo a proposta deste escrito, possibilita-se o exercício crítico da participação política na sociedade, visando um processo de protagonização e emancipação dos alunos enquanto cidadãos criadores, recriadores e pertencentes a um território de uma singular diversidade como o Complexo da Maré.

No escrito (Con) Viver com a loucura: por um cuidado extramuros, Raquel Ferreira Pacheco e Celso Renato Silva nos indicam outro importante território a ser analisado. Procura-se discutir acerca do Centro de Convivência como um serviço substitutivo que, embora sem uma garantia jurídica federal de subsídio e funcionamento, se propõe a intervir potencializando a autonomia e a cidadania aos cidadãos em sofrimento mental, contribuindo para a inserção social dos mesmos, a partir de articulações diversas com a sociedade, por meio da arte. Neste sentido, a autora e o autor problematizam a intolerância existente na sociedade perante a figura do louco e aspectos do estigma que ainda persistem no trato com a loucura.

Mateus Abreu Pereira e Mauricio Rodrigues de Souza nos propõe uma análise acerca da literatura de autoajuda, no texto Literatura de autoajuda, sugestão e contemporaneidade: uma leitura psicanalítica. Nesta proposta, utilizando como principal referencial teórico a psicanálise freudiana e como recurso metodológico uma revisão teórico-bibliográfica, se objetivou analisar alguns dos mecanismos presentes em tal modalidade literária e discutir os fatores que influenciam na sua ampla aceitação hoje. Em termos conclusivos, os autores apontam que a relação estabelecida entre autor e leitor na autoajuda, pautada por processos psíquicos de identificação e transferência em favor da adesão às propostas do autor, permite que este renove continuamente a promessa de conduzir o leitor ao sucesso.

O escrito Uma crítica às estratégias de comunicação na campanha do UNICEF "Está em suas mãos proteger nossas crianças, de Flavia Cristina Silveira Lemos; Ana 
Carolina Farias Franco e Michelle Ribeiro Côrrea, analisa a campanha pelo Fundo das Nações Unidas para a Infância (UNICEF) - "Está em suas mãos proteger nossas crianças" -, elaborada com o objetivo de prevenir e denunciar casos de exploração e violência contra crianças e adolescentes. As autoras apontam que as estratégias de comunicação utilizadas dão pistas de como os efeitos de poder circularam nesse processo, sendo importante as práticas de judicialização da vida e em um denuncismo que opera a defesa e punição, mas pouco contribui à rede de garantia de direitos. Indica-se que, ao dar uma resposta mais imediata, esses serviços tornam-se uma política de emergência e uma ferramenta de luta midiatizada, baseada na denúncia, na lógica penal e no negócio do social.

Adentrando no campo de produção da teoria enativa como constituinte dessa polifonia na Psicologia, Carlos Baum e Renata Kroeff apresentam o artigo Teoria da enação: conceitos introdutórios da obra de Francisco Varela. Neste artigo, o autor e a autora oportunizam uma introdução ao estudo dos processos cognitivos segundo uma perspectiva incorporada da cognição. Para tanto, aborda-se a teoria do biólogo chileno Francisco Varela, a partir de cinco conceitos principais: autonomia, adaptatividade, incorporação, emergência e experiência. Destaca-se a forma como esses conceitos de alinham de maneira a contrapor proposições hegemônicas no campo dos estudos cognitivos, tais como a metáfora do funcionamento da mente como um processamento computacional e a redução dos processos cognitivos à atividade neuronal.

Caroline Garcia, Dolores Galindo e José Carlos Leite, no manuscrito Reencenação como experimento em política, ciência e psicologia: Bergson e Einstein sobre o tempo, colocam em pauta as polarizações proporcionadas no debate entre Bergson e Einstein, ocorrido em 1922, a respeito do tempo, no qual o primeiro teria saído como derrotado. Propõe-se a adoção da reencenação como experimento implica a recusa de uma ontologia plana acerca dos discursos da ciência, além de nos impor, ainda, a própria investigação desses discursos. A perspectiva da teoria ator-rede sobre o estudo de controvérsias permite recuperar o debate épico de 1922 e reinventá-lo por meio da reencenação, pois, ao trazer a concepção de rede como fluxos, circulações, alianças, movimentos, ao invés de remeter a uma entidade cristalizada, dá lugar à reencenação 
como dispositivo de pensamento e de liberdade na criação de campos problemáticos inventivos.

Finalizando o número, trazemos o relato de experiência intitulado $O$ dispositivo das drogas nas políticas públicas, de Francisco Valberdan Pinheiro Montenegro. Neste texto, aborda-se a emergência do dispositivo das drogas nas políticas públicas para o governo da vida e produção de subjetividade. Postas como problema social, as drogas têm sido acionadas sob a forma de ameaça à vida e à sociedade, bem como operacionalizadas enquanto tecnologia de governo. Tendo em vista essa constatação, este manuscrito provoca uma problematização sobre o dispositivo das drogas em sua interface com as políticas públicas partindo da análise de documentos, notícias e registros do diário de campo de um estágio em psicologia no Centro de Atenção Psicossocial - Álcool e outras Drogas (CAPS-AD).

Desejamos uma boa leitura e, mais uma vez, agradecemos a todos e todas que têm colaborado com o periódico Polis e Psique. Esperamos poder contar com vocês, no exercício político possível pela autoria, leitura e elaboração de pareceres.

\section{Henrique Caetano Nardi - Editor Gerente; Neuza Maria de Fátima Guareschi - Editora Associada e Cristiano Hamann - Editor Assistente}

\section{Referências}

Alvarez, J., \& Passos, E. (2014). Cartografar é habitar um território existencial. Em E. Passos; V. Kastrup; L. Escóssia (Orgs.). Pistas do método da cartografia: pesquisa-intervenção e produção de subjetividade. Porto Alegre: Sulina.

Anzaldúa, G. (2005). La conciencia de la mestiza: rumo a uma nova consciência. Revista Estudos Feministas, 13(3), 704-719.

Deleuze, G. \& Guattari, F. (1997). Mil Platôs. Capitalismo e esquizofrenia. São Paulo: Editora 34.

Nardi, H. C. (2016) A Diversidade Epistemológica e a Política da Pesquisa em Psicologia no Brasil: A avaliação tem sido equitativa no interior da área? In: Ferreira, Marcelo Santana; Moraes, Marcia. (Org.). Políticas de Pesquisa em Psicologia Social. Rio de Janeiro: Nova Aliança.

Tourinho, E. Z. (2001). A produção de conhecimento em Psicologia: a análise do comportamento. I Simpósio O Homem e o Método e II Encontro das Escolas de Psicologia de Belo Horizonte. Belo Horizonte, MG. 